\title{
Article \\ Stability and Influence of Storage Conditions on Nanofibrous Film Containing Tooth Whitening Agent
}

\author{
Siriporn Okonogi ${ }^{1,2, *}$, Adchareeya Kaewpinta ${ }^{3}$ (D) and Pisaisit Chaijareenont ${ }^{2,4}$ \\ 1 Department of Pharmaceutical Sciences, Faculty of Pharmacy, Chiang Mai University, \\ Chiang Mai 50200, Thailand \\ 2 Research Center of Pharmaceutical Nanotechnology, Chiang Mai University, Chiang Mai 50200, Thailand; \\ pisaisit.c@cmu.ac.th \\ 3 Interdisciplinary Program in Nanoscience and Nanotechnology, Faculty of Science, Chiang Mai University, \\ Chiang Mai 50200, Thailand; adchareeya_k@cmu.ac.th \\ 4 Department of Prosthodontics, Faculty of Dentistry, Chiang Mai University, Chiang Mai 50200, Thailand \\ * Correspondence: siriporn.okonogi@cmu.ac.th; Tel.: +66-53-944-311
}

Citation: Okonogi, S.; Kaewpinta, A.; Chaijareenont, P. Stability and Influence of Storage Conditions on Nanofibrous Film Containing Tooth Whitening Agent. Pharmaceutics 2021, 13, 449. https://doi.org/10.3390/ pharmaceutics 13040449

Academic Editor: Kishor M. Wasan

Received: 27 February 2021

Accepted: 20 March 2021

Published: 26 March 2021

Publisher's Note: MDPI stays neutral with regard to jurisdictional claims in published maps and institutional affiliations.

Copyright: () 2021 by the authors. Licensee MDPI, Basel, Switzerland. This article is an open access article distributed under the terms and conditions of the Creative Commons Attribution (CC BY) license (https:// creativecommons.org/licenses/by/ $4.0 /)$.

\begin{abstract}
Carbamide peroxide (CP), a tooth whitening agent, is chemically unstable. The present study explores stability enhancement of CP by loading in a nanofibrous film (CP-F) composed of polyvinyl alcohol/polyvinylpyrrolidone/silica mixture, using an electrospinning technique. Kept at a temperature range of $60-80^{\circ} \mathrm{C}$ for $6 \mathrm{~h}, \mathrm{CP}$ in $\mathrm{CP}-\mathrm{F}$ showed significantly higher stability than that in a polymer solution and in water, respectively. Degradation of CP in CP-F could be described by the first order kinetics with the predicted half-life by the Arrhenius equation of approximately 6.52 years. Physicochemical properties of CP-F after long-term storage for 12 months at different temperatures and relative humidity $(\mathrm{RH})$ were investigated using scanning electron microscopy, $\mathrm{X}$-ray diffractometry, differential scanning calorimetry, and Fourier transform infrared spectroscopy. It was found that high temperature and high humidity $\left(45^{\circ} \mathrm{C} / 75 \% \mathrm{RH}\right)$ could enhance water absorption and destruction of the nanofibrous structure of CP-F. Interestingly, kept at $25^{\circ} \mathrm{C} / 30 \% \mathrm{RH}$, the nanofibrous structure of $\mathrm{CP}-\mathrm{F}$ was not damaged, and exhibited no water absorption. Moreover, the remaining $\mathrm{CP}$, the mechanical properties, and the adhesive properties of $\mathrm{CP}-\mathrm{F}$ were not significantly changed in this storage condition. It is concluded that the developed CP-F and a suitable storage condition can significantly improve CP stability.
\end{abstract}

Keywords: carbamide peroxide; nanofibrous film; stability; stability kinetics; physicochemical properties; storage

\section{Introduction}

Carbamide peroxide (CP) is an active ingredient for tooth whitening [1]. This compound is known as urea peroxide or hydrogen peroxide-urea. CP was first used as an anti-inflammatory and antiseptic for the treatment of periodontal diseases and gingivitis [2,3]. However, tooth whitening occurred as a side effect during the treatments [4]. The whitening action of $\mathrm{CP}$ resulted from a chemical oxidative process involving the peroxide and organic pigmented molecules in enamel and dentine. The change in the structure of the pigmented molecules resulted in clearer, smaller molecules, and the teeth appeared white [5-7]. Due to the increased interest in the esthetics of healthy white teeth, dental whitening procedures became more popular [8] and tooth whitening products containing $\mathrm{CP}$ are widely used. Other applications of CP in the oral cavity are for the treatment of plaque, gingivitis, and caries, by its antibacterial and anti-inflammatory activities [9-11].

Despite its attractive properties, CP is chemically unstable [12]. It is highly sensitive to light and thermal exposure [13]. These factors are the main cause of CP degradation upon storage and result in a reduction in tooth whitening efficacy [14]. Many stabilizers and deterioration inhibitors have been used for preventing CP degradation. However, the 
stabilizers are varied in their effectiveness and exhibit disadvantages such as being expensive, failing to prevent effervescence, imparting undesirable color, or lacking sufficient solubility [15]. The aqueous formulations containing tooth whitening agents show the severe disadvantage of poor stability during long-term storage [16], leading to the products losing their tooth whitening potency [17].

The development in pharmaceutical technology has made it possible to produce functional formulations to overcome drug problems such as low stability [18]. Encapsulation of a drug in a dry form of nanofibrous film with diameters in the nano range by electrospinning technique is currently gaining a large interest, due to its simplicity, capacity to produce non-woven nanofibrous film with a high surface to volume ratio, low cost, and capability of scale-up production $[19,20]$. The electrospun nanofibrous film is a viable formulation that can allow active compounds to be incorporated with an appropriate polymer or polymer mixture. Considering that $\mathrm{CP}$ is highly unstable, particularly in aqueous systems, drug delivery in terms of solid formulation such as nanofibrous film should be a good candidate for delivery of this agent. In addition, the nanofibrous film formulation can increase patient compliance due to its convenience of use [21].

Recently, we reported that CP-loaded nanofibrous film (CP-F) could be produced by electrospinning technique for tooth whitening [22]. Polyvinyl alcohol (PVA) was used as a base solution for electrospinning nanofibrous film production. Polyvinylpyrrolidone (PVP) and silica helped to stabilize the $\mathrm{CP}$ and were used as drug carriers for the prevention of $\mathrm{CP}$ degradation during the process. The developed $\mathrm{CP}$ nanofibrous film exhibited high drug entrapment efficacy and tooth whitening activity. However, the stability of $\mathrm{CP}$ in the developed CP-F has not yet been comprehensively investigated. Therefore, stability tests of this novel formulation to predict monitoring and to determine the validity and the ideal storage conditions are needed. Stability testing of formulations could provide evidence of the quality of the formulation and the influence of environmental factors, such as temperature, light, and humidity [23]. The evidence can be applied to developing a suitable manufacturing process, selecting packaging, and storage conditions. Therefore, the aim of the present study was to investigate the stability of CP in CP-F after keeping it in various conditions. The degradation kinetics were studied to estimate the half-life and shelf-life of the developed products. The physicochemical properties of CP-F were characterized and the amount of $\mathrm{CP}$ remaining in $\mathrm{CP}-\mathrm{F}$ was determined to evaluate the efficiency of $\mathrm{CP}-\mathrm{F}$ on stabilization of $\mathrm{CP}$.

\section{Materials and Methods}

\subsection{Materials}

CP, PVA (molecular weight $=85,000-124,000$, degree of hydrolysis $=87-89 \%$ ), PVP, $\mathrm{N}, \mathrm{N}$-dimethylformamide, urea, and triphenylphosphine were obtained from Sigma Aldrich (St. Louis, MO, USA). Hydrophilic fumed silica was from Evonik (Aerosil 380F, Essen, Germany).

\subsection{Preparation of $C P-F$}

Preparation of $\mathrm{CP}-\mathrm{F}$ was according to the procedure reported in previous work [22]. Briefly, CP solution composed of PVA, PVP, silica, CP, and water in a weight ratio of 5.5:3:1:0.5:90 was firstly prepared by dissolving PVA and PVP in distilled water, and continuously stirred at $70{ }^{\circ} \mathrm{C}$ for $12 \mathrm{~h}$. The prepared PVA-PVP solution was cooled to room temperature. Silica and $\mathrm{CP}$ were weighed and dispersed in $1 \% \mathrm{~N}, \mathrm{~N}$-dimethylformamide. Afterwards, the prepared PVA-PVP solution was added to this solution until the final concentration of $\mathrm{CP}$ was $0.5 \%$. The sample was gently stirred until a clear solution was obtained. This $\mathrm{CP}$ solution was used for electrospinning. For fabrication of $\mathrm{CP}-\mathrm{F}$, the electrospinning process was performed. The setup consisted of a high-voltage power supply (FC Series Glassman High Voltage Regulated DC Power Supplies, High Bridge, NJ, USA), a syringe connected with a pump (Harvard Apparatus Pump 11 Elite Syringe Pumps, Holliston, MA, USA), and a stationary metal collector (VWR International, Radnor, 
PA, USA) covered with aluminum foil. The prepared CP solution for electrospinning was transferred to a syringe fitted with a stainless-steel needle (Hamilton $2.5 \mathrm{~mL}$, Model 1005 TLL SYR, Hamilton Metal Hub Needles, Bonaduz, Switzerland) and was horizontally pumped at a flow rate of $10 \mu \mathrm{L} / \mathrm{min}$. The electrospinning was set at $15 \mathrm{kV}$ and the distance between the syringe tip and the collector plate was $10 \mathrm{~cm}$. Prior to the further test, the obtained CP-F was cut into $10 \mathrm{~mm} \times 50 \mathrm{~mm}$ and measured for thickness at 10 points using a micrometer (INSIZE 3203-25A, Suzhou, China). The thickness value was confirmed by optical microscope (Axio Vert.A1 FL-LED, ZEISS, Oberkochen, Germany) equipped with a digital camera (ZEISS Axiocam 105 color). The sample was cut in a cross-sectional direction and vertically fixed on a glass slide. Photomicrographs of the samples were examined at magnification $5 \times$ and measured for thickness by Image J software (US National Institutes of Health, Bethesda, MD, USA). CP in polymer solution (CP-P) was prepared by dissolving $\mathrm{CP}$ in a polymer solution containing $5.5 \% \mathrm{PVA}, 3 \% \mathrm{PVP}$, and $1 \%$ silica to have a final $\mathrm{CP}$ concentration of $5 \%$. CP in water solution (CP-W) was obtained from dissolving $\mathrm{CP}$ in distilled water to obtain a final concentration of $\mathrm{CP}$ the same as $\mathrm{CP}-\mathrm{P}$. The amount of $\mathrm{CP}$ was analyzed using high-performance liquid chromatography (HPLC).

\subsection{HPLC Analysis}

For the determination of CP remaining in the samples, HPLC (Hewlett Packard series 1100, Agilent Technologie, Santa Clara, CA, USA) was performed, and HPLC condition from previous reports [24] was used with some modifications. Briefly, an amount of $0.1 \mathrm{~g}$ of sample was dissolved in $10 \mathrm{~mL}$ deionized water, then the solutions were centrifuged using a Sorvall ${ }^{\mathrm{TM}}$ ST16R Centrifuge (Thermo Fisher Scientific, Waltham, MA, USA) with a speed of $10,000 \mathrm{rpm}$ for $15 \mathrm{~min}$. An amount of $1000 \mu \mathrm{L}$ of the collected samples was mixed with $1000 \mu \mathrm{L}$ of $0.1 \mathrm{M}$ triphenylphosphine and stirred for $2 \mathrm{~h}$ with light protection. The determination was carried out at $25 \pm 0.2^{\circ} \mathrm{C}$. A reversed-phase column $(4.6 \mathrm{~mm} \times$ $250 \mathrm{~mm}$ Hypersil ODS Agilent technologies, Santa Clara, CA, USA) was used and detected at $225 \mathrm{~nm}$. The injection volume was $10 \mu \mathrm{L}$. A mobile phase at different ratios of acetonitrile to water was run with a flow rate of $1.0 \mathrm{~mL} / \mathrm{min}$. At the starting of running time, a volume ratio of 50:50 was used until $6.5 \mathrm{~min}$. After that, the mobile phase ratio was changed to 100:0. At $10 \mathrm{~min}$, the mobile phase ratio was changed back to 50:50 until the complete run time of $25 \mathrm{~min}$ was reached. The calibration curve was prepared using an aqueous solution of $\mathrm{CP}$ at a range of 50-200 $\mu \mathrm{g} / \mathrm{mL}$. A linear standard curve was obtained with a correlation coefficient $\left(r^{2}\right)$ of 0.9997 . The amount of CP remaining was calculated using Equation (1):

$$
\% \mathrm{CP} \text { remaining }=\frac{\mathrm{CP}_{\mathrm{a}}}{\mathrm{CP}_{\mathrm{i}}} \times 100,
$$

where $\mathrm{CP}_{\mathrm{a}}$ was the analyzed amount of $\mathrm{CP}$ at the time interval and $\mathrm{CP}_{\mathrm{i}}$ was the amount of $\mathrm{CP}$ initially in the sample. The results obtained from all storage conditions were plotted as $\%$ drug remaining versus time.

\subsection{Effects of Temperature and UV Light on Degradation Kinetics of $C P$}

To investigate the thermal degradation kinetics of $\mathrm{CP}$, the samples were placed in the accelerated temperature conditions of $60^{\circ} \mathrm{C}, 70^{\circ} \mathrm{C}$, and $80^{\circ} \mathrm{C}$. Exact amounts of $20 \mathrm{mg}$ of CP-F, CP-P, and CP-W were weighed in $1.5 \mathrm{~mL}$ microcentrifuge tubes and placed in a heating incubator (MD-MINI, major science, Saratoga, CA, USA), and protected from light. To investigate the effects of UV light, the samples were placed in a closed chamber and exposed to UV light at $254 \mathrm{~nm}$ using a $35 \mathrm{~W}$, CKL T5 fluorescent lamp (Zhongshan Okes Lighting Appliance Co.,Ltd, Guangdong, China) at a constant temperature of $25^{\circ} \mathrm{C}$. A control was performed by placing the samples in a closed chamber without UV light exposure at the same temperature. The samples were collected after exposure times of 60 , $120,180,240,300$, and $360 \mathrm{~min}$. The remaining amount of CP was analyzed using HPLC. The experiments were performed in triplicate. 


\subsection{Effects of Temperature and Humidity on CP-F after Long-Term Storage}

A long-term stability study of $\mathrm{CP}-\mathrm{F}$ was carried out for a period of 12 months at three different conditions: $25{ }^{\circ} \mathrm{C} / 30 \%$ relative humidity $(\mathrm{RH}), 25^{\circ} \mathrm{C} / 75 \% \mathrm{RH}$, and $45{ }^{\circ} \mathrm{C} / 30 \%$ $\mathrm{RH}$. For conditions of $30 \%$ and $75 \% \mathrm{RH}$, the samples were stored in desiccators equilibrated with the saturated solutions of magnesium chloride and sodium chloride, respectively. The samples were analyzed in terms of physical properties after 12 months of storage, in comparison with those of an initial preparation as a control. The remaining amount of CP at time intervals of 1, 2, 3, 6, 9, and 12 months was determined using HPLC. The experiment was carried out in triplicate for each sample in all storage conditions.

\subsection{Color Measurement}

The color of CP-F was analyzed using a colorimeter (Fru WR10 portable precision colorimeter, Shenzhen wave optoelectronics technology Co.,Ltd, Shenzhen, China). The measurements were taken from three different points on the surface of $\mathrm{CP}-\mathrm{F}$. Color measurement outcomes were evaluated under the CIE (Commission International d'Eclaraige) $L^{*} a^{*} b^{*}$ coordinate values, where $L^{*}$ represents the degree of lightness ranging from 0 (zero) to 100 (white), and $\mathrm{a}^{*}$ and $\mathrm{b}^{*}$ represent the degree of green-red and the degree of blue-yellow color coordinates, respectively [25]. A positive $a^{*}$ value indicates the degree of red and a negative $a^{*}$ value indicates the degree of green. A positive $b^{*}$ value indicates the degree of yellow and a negative $b^{*}$ value indicates the degree of blue. The center of the $a^{*}$ and $b^{*}$ coordinates is achromatic and the increasing values of $a^{*}$ and $b^{*}$ represent the saturation of the color. The $\mathrm{L}^{*} \mathrm{a}^{*} \mathrm{~b}^{*}$ values of CP-F were measured. To evaluate the color change between the color of CP-F initially and 12 months after storage, the total color difference $(\Delta \mathrm{E})$ was calculated using Equation (2). The $\Delta \mathrm{E}$ value relates to the visual perception of color. If the $\Delta \mathrm{E}$ values are below 1 , the color change cannot be visible, if the $\Delta \mathrm{E}$ values are 1 to 3 , a minor color change is visible, and if the $\Delta \mathrm{E}$ values are above 3 , the color change is obviously visible. The color measurement was performed at 5 points from three independent samples at each storage condition.

$$
\Delta \mathrm{E}=\left[(\Delta \mathrm{L} *)^{2}+(\Delta \mathrm{a} *)^{2}+(\Delta \mathrm{b} *)^{2}\right]^{1 / 2} .
$$

\subsection{Morphology Study}

The morphology of CP-F before and after storage was observed using a scanning electron microscope (SEM, JSM 5910 LV, Tokyo, Japan). The samples were cut to small sections of approximately $0.5 \mathrm{~cm} \times 0.5 \mathrm{~cm}$ and were attached to the stubs by using doublesided carbon tape. The samples were coated with gold by a sputter coater before SEM observation. SEM images were taken at 3000 and 10,000 magnifications with an excitation voltage of $15 \mathrm{kV}$. The average diameter of CP-F was measured using Image J software (US National Institutes of Health, Bethesda, MD, USA).

\subsection{Internal Structure Investigation}

X-ray diffraction (XRD) was undertaken using a Rigaku SmartLab X-ray diffractometer (Rigaku, Tokyo, Japan). A Bragg angle (2 $\theta$ ) was used at a range of $10^{\circ}$ to $60^{\circ}$. The samples were placed on an etched glass slide and scanned at a rate of $12^{\circ} / \mathrm{min}$. For comparison, the $\mathrm{XRD}$ analysis of intact $\mathrm{CP}$ and the blank nanofibrous film was also performed.

\subsection{Thermal Behavior Investigation}

The thermal behavior of $\mathrm{CP}-\mathrm{F}$ was investigated using differential scanning calorimetry (DSC, DSC 8000, PerkinElmer, Waltham, MA, USA). The samples of approximately 1-3 mg were accurately weighed, and were transferred into aluminum pans and hermetically sealed. Subsequently, the samples were heated from 0 to $250{ }^{\circ} \mathrm{C}$ at the heating rate of $10^{\circ} \mathrm{C} / \mathrm{min}$ under nitrogen flow at $40 \mathrm{~mL} / \mathrm{min}$. For comparison, the thermal analysis of intact $\mathrm{CP}$ and the blank nanofibrous film was also performed. 


\subsection{Molecular Interaction Study}

Fourier transform infrared spectroscopy (FTIR) was performed to investigate the molecular interaction of the samples using a Thermo Nicolet NEXUS 470 FT-IR (Thermo electron corporation, Thermo Fisher Scientific, Waltham, MA, USA) connected with a Smart diffuse reflectance FTIR accessory (Thermo electron corporation, Thermo Fisher Scientific, Waltham, MA, USA). Spectra were recorded at $25^{\circ} \mathrm{C}$ in the scanning range of $4000-600 \mathrm{~cm}^{-1}$. The transmittance mode was used with a resolution of $4 \mathrm{~cm}^{-1}$ and 64 scans. Data recording was done through OMNIC software (Thermo Fisher Scientific Waltham, MA, USA). For comparison, FTIR analysis of CP powder and the blank nanofibrous film was also performed.

\subsection{Mechanical Property Investigation}

Mechanical properties of CP-F were evaluated using a texture analyzer (TA.XT Plus, Texture Analyzer Stable Micro Systems, Surrey, UK) by the method previously described [26], with some modification. Prior to testing, a texture analyzer was calibrated with a $5 \mathrm{~kg}$ load cell and equipped with tensile grips (A/TG). CP-F was cut into a rectangular shape of $0.5 \mathrm{~cm} \times 5.0 \mathrm{~cm}$. The sample was clamped between the grips. The initial length between grips was set at $3 \mathrm{~cm}$. The test speed was $1 \mathrm{~mm} / \mathrm{s}$ with $5 \mathrm{~g}$ of trigger force. The sample was pulled until the breaking of the sample occurred. At the point of breaking, the value of force and elongation was recorded. The measurement was done with three independent film samples from each storage condition. The mechanical properties of the films were characterized by the tensile strength $(\sigma)$, elongation at break $(\varepsilon)$, and Young's modulus (E), calculated by using Equations (3)-(5), respectively:

$$
\begin{aligned}
\sigma & =\frac{\mathrm{F}}{\mathrm{A}}, \\
\varepsilon & =\frac{\Delta \mathrm{L}}{\mathrm{L}_{0}}, \\
\mathrm{E} & =\frac{\sigma}{\varepsilon},
\end{aligned}
$$

where $\mathrm{F}$ is the maximum force at the films breaking $(\mathrm{N}), \mathrm{A}$ is the cross-sectional area of the sample $\left(\mathrm{cm}^{2}\right), \Delta \mathrm{L}$ is the extension of the sample, and $\mathrm{L}_{0}$ is the original length of the sample $(\mathrm{cm})$.

\subsection{Mucoadhesive Property Investigation}

A texture analyzer (TA.XT Plus Texture Analyzer, Stable Micro Systems, Surrey, UK) was utilized to investigate the adhesive properties of CP-F using a method previously described [22], with some modification. Prior to testing, a texture analyzer was calibrated with a $5 \mathrm{~kg}$ load cell. CP-F was attached to the probe (P 0.5 Perspex, 0.5 -inch diameter) using double-sided adhesive tape. A piece of $2 \mathrm{~cm} \times 5 \mathrm{~cm}$ porcine intestinal mucosa was attached to a glass slide and then placed on the stand. The surface of the mucosa was hydrated by dropping $1 \mathrm{~mL}$ of artificial saliva. The probe was lowered to contact the mucosal surface. A contact force of $0.2 \mathrm{~N}$ was applied with a contact time of $60 \mathrm{~s}$, and then the probe was withdrawn at the rate of $1 \mathrm{~mm} / \mathrm{s}$. The Texture Exponent software (Stable Micro Systems, Surrey, UK) was used to determine the adhesive force. The experiment was conducted in triplicate for the film samples from each storage condition.

\subsection{Statistical Analysis}

Descriptive statistics for continuous variables were calculated and expressed as mean \pm standard deviation (SD). Significance was assessed by one-way analysis of variance (ANOVA) and followed by Duncan's multiple range test, using Statistic SPSS version 22 (SPSS Inc., Chicago, IL, USA). The significance level was set at $p<0.05$. 


\section{Results and Discussion}

The purpose of stability testing is to obtain information on how the quality of a formulation varies with time under the influence of various environmental factors, such as temperature, humidity, and light. The obtained results can lead to establishing the recommended suitable storage conditions of the formulations. The stability of a drug refers to the chemical and physical integrity of the dosage and the ability of the formulation to maintain drug content. In the present study, short-term $(6 \mathrm{~h})$ and long-term (12 months) stabilities of CP-F were investigated, mainly to evaluate the degradation kinetics and the gradually chemical changes of $\mathrm{CP}$ in $\mathrm{CP}-\mathrm{F}$, respectively, as well as the physicochemical changes after long storage in constraining conditions.

It was found that most fabricated CP-F had a uniform thickness. Using a micrometer, the films showed an average thickness of $0.98 \pm 0.10 \mathrm{~mm}$. The cross-section photomicrograph from optical microscopy of $\mathrm{CP}-\mathrm{F}$ as presented in Figure 1 showed that the thickness of the films was $1.00 \pm 0.05 \mathrm{~mm}$, which was in accordance with the result from the micrometer. The obtained CP-F having a thickness of approximately $1 \mathrm{~mm}$ were selected to further study.

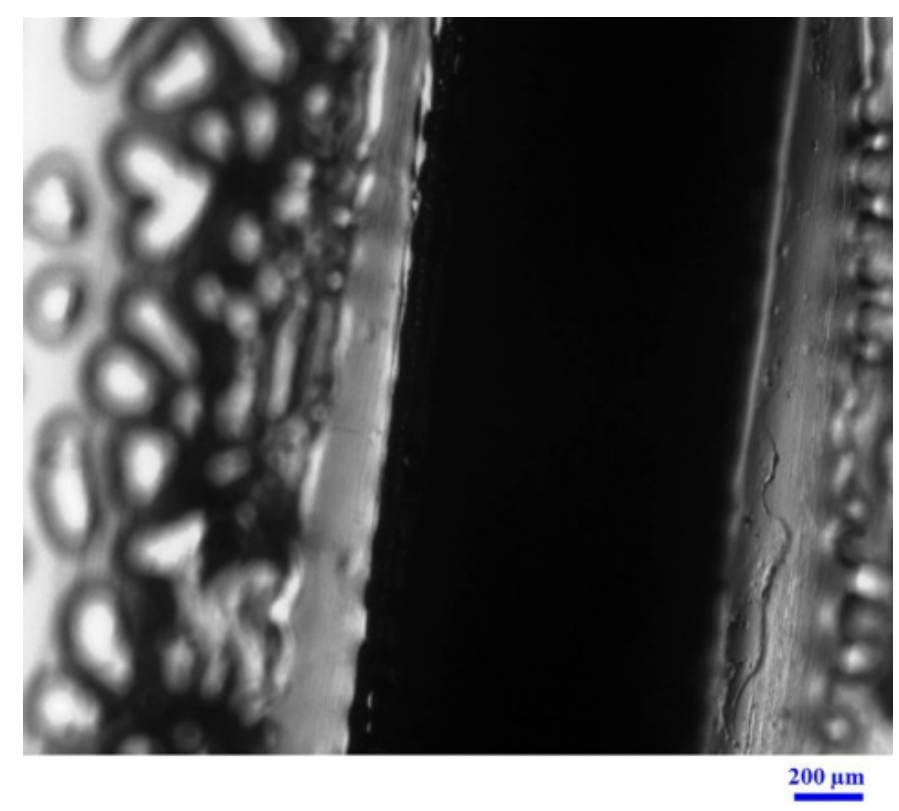

Figure 1. Photomicrographs from an optical microscopy of the cross-section of CP-loaded nanofibrous film (CP-F).

In general, the HPLC analysis used for the determination of CP in the formulation was validated by the selectivity of triphenylphosphine oxide and triphenylphosphine. The HPLC chromatogram peaks of triphenylphosphine oxide and triphenylphosphine were presented in the different retention times of $5.0 \mathrm{~min}$ and $10.5 \mathrm{~min}$, respectively, as shown in Figure S1a [27]. Triphenylphosphine oxide was obtained from the oxidation of triphenylphosphine by $\mathrm{CP}$ [28]. In the present study, the determination of $\mathrm{CP}$ was obtained from the triphenylphosphine oxide peak area. The residual peak of triphenylphosphine in the HPLC chromatograms confirmed that all CP was completely reacted. Moreover, to limit oxidative interference from other factors that might lead to an overestimation of $\mathrm{CP}$, the determination of triphenylphosphine oxide in a blank sample without $\mathrm{CP}$ was performed, and the result is shown in Figure S1b.

\subsection{Thermal Degradation Kinetics}

After thermal stress conditions, the results showed that the increase in temperature and exposure time led to an increase in $\mathrm{CP}$ degradation. $\mathrm{CP}$ content in all samples was significantly rapidly decreased from its initial value after heat exposure $(p<0.05)$. After 
$6 \mathrm{~h}$ of heating at $80{ }^{\circ} \mathrm{C}$, the amount of $\mathrm{CP}$ remaining was found to be the lowest in all formulations compared to other temperatures at the same exposure time. However, the levels of $\mathrm{CP}$ degradation for each sample were different. CP remaining in CP-F was significantly higher $(61.51 \pm 0.26 \%)$ than that in CP-P $(32.03 \pm 2.24 \%)$ and CP-W $(4.38$ $\pm 2.16 \%$ ). To evaluate the degradation kinetics of CP in the formulations, the collected experimental data were calculated based on a reaction rate expression using Equation (6):

$$
\frac{-\mathrm{d}[\mathrm{C}]}{\mathrm{dt}}=\mathrm{k}[\mathrm{C}]^{\mathrm{n}}
$$

where $\mathrm{C}$ is the concentration of $\mathrm{CP}(\mu \mathrm{g} / \mathrm{mL}), \mathrm{t}$ is the incubation time (min), $\mathrm{k}$ is the degradation rate constant $\left(\mathrm{min}^{-1}\right)$, and $\mathrm{n}$ is the order of the reaction where $\mathrm{n}=0$ is zero order and $n=1$ is first order. The order of drug degradation was determined using graphical methods. The remaining concentration of $\mathrm{CP}$ and the natural logarithm remaining $\mathrm{CP}$ were plotted versus time for prediction of zero order and first order degradations, respectively. The results are shown in Figure $2 a, b$. The linear regression was added to determine the correlation coefficient $\left(r^{2}\right)$. As presented in Table 1 , the obtained $r^{2}$ values from the first order reaction plots were close to 1 , suggesting that the thermal degradation of $\mathrm{CP}$ followed the first order kinetics. The kinetic parameters obtained from fitting the first order kinetics model are shown in Table 2. The results demonstrate that the elevated temperature could significantly cause an increase in the degradation rate of $\mathrm{CP}$. The results also confirm that $\mathrm{CP}$ in CP-F possessed significantly higher stability than in CP-P and CP-W $(p<0.05)$.

(a)

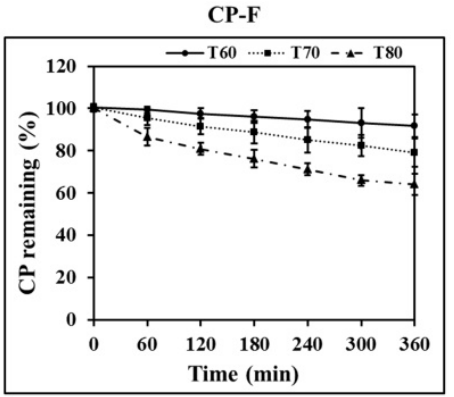

(b)
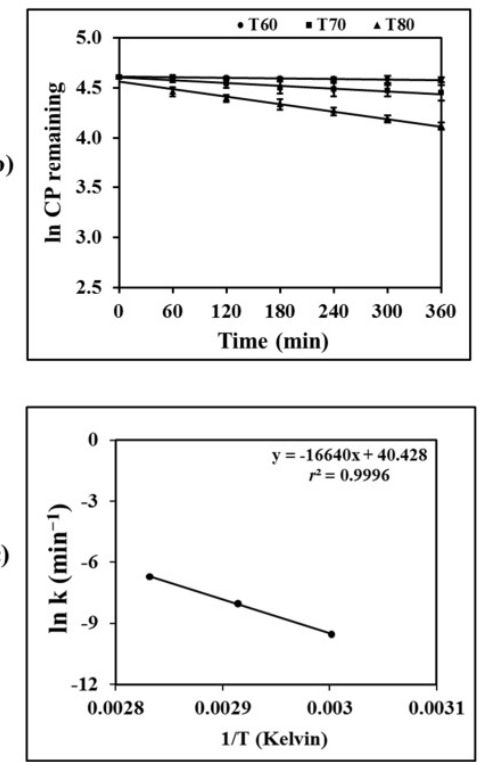
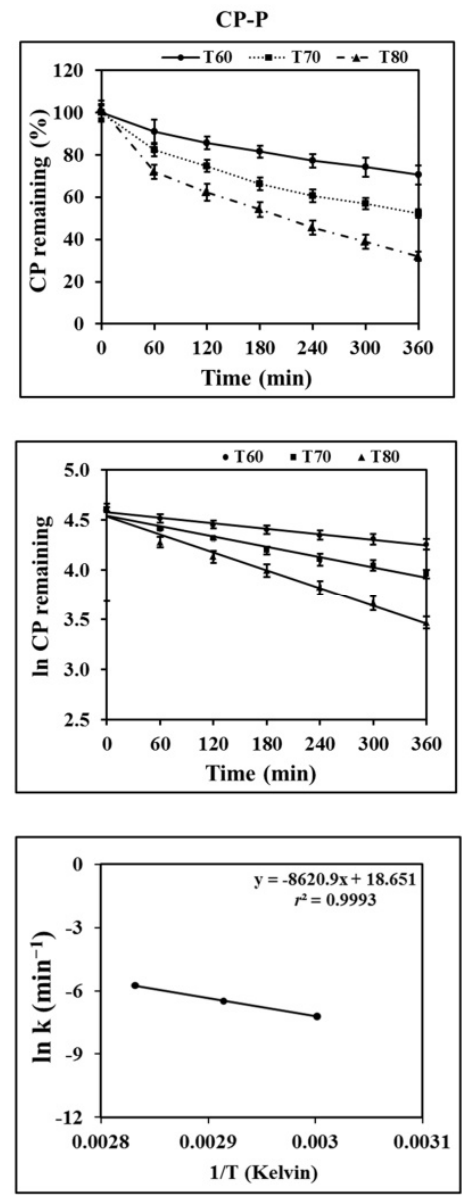
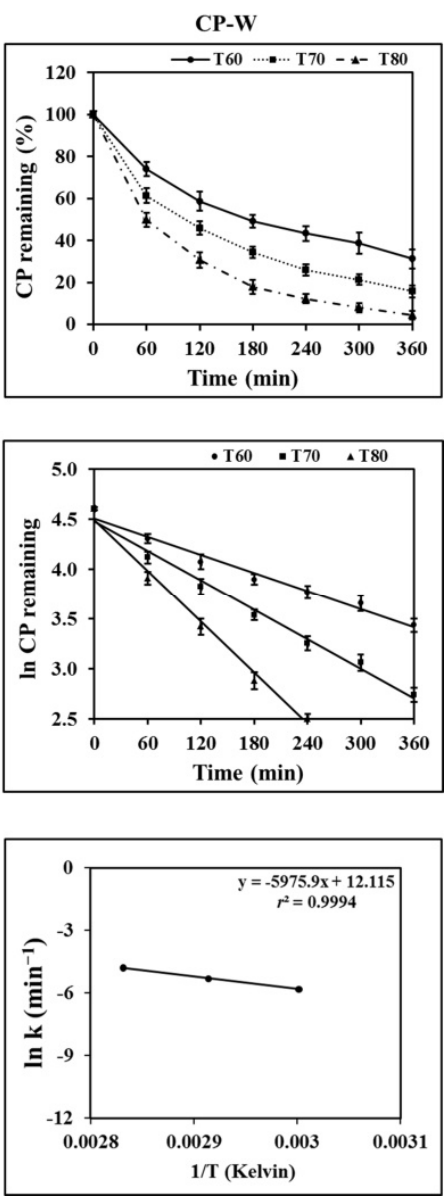

Figure 2. Degradation profiles of $\mathrm{CP}$ under heat exposure, (a) zero order plots, (b) first order plots, and (c) Arrhenius plots. 
Table 1. The $r^{2}$ values of a linear regression from zero and first order plots of carbamide peroxide (CP) degradation by heat exposure.

\begin{tabular}{ccccccc}
\hline \multirow{2}{*}{$\begin{array}{c}\text { Temperature } \\
\left({ }^{\circ} \mathbf{C}\right)\end{array}$} & \multicolumn{3}{c}{ Zero Order } & \multicolumn{3}{c}{ First Order } \\
\cline { 2 - 7 } & $\mathbf{C P - F}$ & CP-P & CP-W & CP-F & CP-P & CP-W \\
\hline 60 & 0.95 & 0.95 & 0.90 & 0.99 & 0.99 & 0.98 \\
70 & 0.95 & 0.93 & 0.86 & 0.99 & 0.98 & 0.99 \\
80 & 0.94 & 0.91 & 0.78 & 0.98 & 0.98 & 0.99 \\
\hline
\end{tabular}

Table 2. Average thermal degradation rate constant of $\mathrm{CP}$ in each formulation estimated by the first order kinetics.

\begin{tabular}{|c|c|c|c|}
\hline \multirow{2}{*}{$\begin{array}{c}\text { Temperature } \\
\left({ }^{\circ} \mathrm{C}\right)\end{array}$} & \multicolumn{3}{|c|}{$\mathrm{k}\left(\times 10^{-4} \mathrm{~min}^{-1}\right) *$} \\
\hline & $\mathrm{CP}-\mathrm{F}$ & CP-P & $\mathrm{CP}-\mathrm{W}$ \\
\hline 60 & $0.72 \pm 0.13^{c}$ & $7.36 \pm 1.21^{b}$ & $30.47 \pm 1.58^{a}$ \\
\hline 70 & $3.25 \pm 0.84^{\mathrm{c}}$ & $15.14 \pm 1.80^{b}$ & $49.17 \pm 1.78^{a}$ \\
\hline 80 & $12.23 \pm 1.49^{c}$ & $31.54 \pm 3.49^{b}$ & $82.33 \pm 3.14^{a}$ \\
\hline
\end{tabular}

The acceleration effect of temperature on the rate of chemical reactions is generally described by the Arrhenius equation [29], which is the relationship between the rate constant and temperature, as shown in Equation (7):

$$
\mathrm{k}=\mathrm{Ae} \mathrm{e}^{-\mathrm{Ea} / \mathrm{RT}} \text {, }
$$

where $\mathrm{k}$ is the reaction rate constant of first order kinetic $\left(\mathrm{min}^{-1}\right), \mathrm{A}$ is the frequency factor, Ea is the activation energy $\left(\mathrm{cal} \mathrm{mol}^{-1}\right), \mathrm{R}$ is the gas constant $\left(1.987 \mathrm{cal} \mathrm{mol}^{-1} \mathrm{~K}^{-1}\right)$, and $\mathrm{T}$ is the absolute temperature in degrees Kelvin. The determination of the Arrhenius parameter is based on a plot of the natural logarithm of $\mathrm{k}$ against the reciprocal of absolute temperature $(1 / \mathrm{T})$. Estimation of the appropriate rate or rate constant for $\mathrm{CP}$ degradation is an important step in predicting the stability of $\mathrm{CP}$ in each formulation. From the results, the Arrhenius plots provide a good description of $\mathrm{CP}$ degradation, as it is evident from the linearity $\left(r^{2}=0.99\right)$ of the plots as seen in Figure $2 c$ for all formulations. The Ea value for $\mathrm{CP}$ degradation in each formulation was calculated according to the Arrhenius plots. It was found that the Ea value of CP in CP-F was higher than that in CP-P and CP-W, with the values of $33.06 \pm 0.83,17.01 \pm 0.69$, and $11.87 \pm 0.49 \mathrm{kcal} / \mathrm{mol}$, respectively. The results suggested that the activation energy for $\mathrm{CP}$ degradation in the nanofibrous film is approximately two times higher than $\mathrm{CP}$ in the polymer solution and three times higher than $\mathrm{CP}$ in the water solution. These results show the high potential of the nanofibrous film for the protection of $\mathrm{CP}$ from thermal degradation.

According to the Arrhenius plots, the degradation rate constant to room temperature $\left(\mathrm{k}_{25}\right)$ of CP from each formulation can be estimated. It was found that the $\mathrm{k}_{25}$ of CP in CP-F was approximately $2.1 \times 10^{-7} \mathrm{~min}^{-1}$ and that in CP-P and CP-W it was $3.5 \times 10^{-5}$ and $36.0 \times 10^{-5} \mathrm{~min}^{-1}$, respectively. The obtained $\mathrm{k}_{25}$ values were used for the calculation of the half-life and shelf-life of CP-F using Equations (8) and (9), respectively:

$$
\mathrm{t}_{1 / 2}=\frac{0.693}{\mathrm{k}_{25}},
$$

and

$$
\mathrm{t}_{90}=\frac{0.105}{\mathrm{k}_{25}},
$$

where $\left(t_{1 / 2}\right)$ is the half-life and $t_{90}$ is the shelf-life of CP-F. It was found that the half-life of CP-F was $6.5 \pm 0.2$ years, much higher than that of $\mathrm{CP}-\mathrm{P}$ and $\mathrm{CP}-\mathrm{W}$, which showed the half-life values of $13.8 \pm 0.8$ and $1.3 \pm 0.2$ days, respectively. The shelf-life was calculated 
to ensure that at least $90 \%$ of CP remain in the formulation and the results demonstrated that the shelf-life of CP-F was $1.01 \pm 0.03$ years, much higher than that of CP-P and CP$\mathrm{W}$, which demonstrated shelf-life values of only $50.2 \pm 2.33$ (approximately 2 days) and $4.71 \pm 0.63 \mathrm{~h}$, respectively. From these results, the effects of nanofibrous film on retardation of CP degradation from the thermal environment was obviously seen.

\subsection{Degradation Kinetics of CP by UV Light}

The evaluation of the photostability of the drugs and the formulations is an essential issue for formulation development. Tooth whitening agents such as hydrogen peroxide and $\mathrm{CP}$ are photosensitive agents $[30,31]$; therefore, their formulated products may degrade during manufacturing and storage. In the present study, the photostability tests of the formulations were carried out under UV light. As shown in Figure 3a, after the samples were exposed to UV light for $1 \mathrm{~h}, \mathrm{CP}-\mathrm{F}$ showed a higher proportion of $\mathrm{CP}$ remaining than $\mathrm{CP}-\mathrm{P}$ and $\mathrm{CP}-\mathrm{W}$. The CP content of CP-P and CP-W significantly decreased when compared to the initial measurement $(p<0.05)$, whereas that of CP-F was not significantly different from the initial measurement. The CP remaining of all formulations showed a significant difference from the initial measurement $(p<0.05)$ after $4 \mathrm{~h}$ exposure to UV light.

(a)

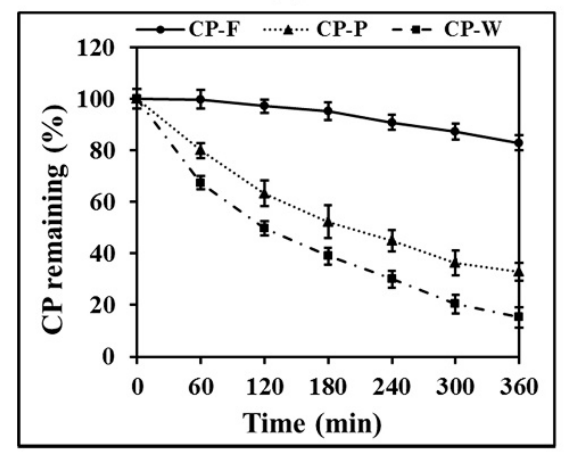

(b)

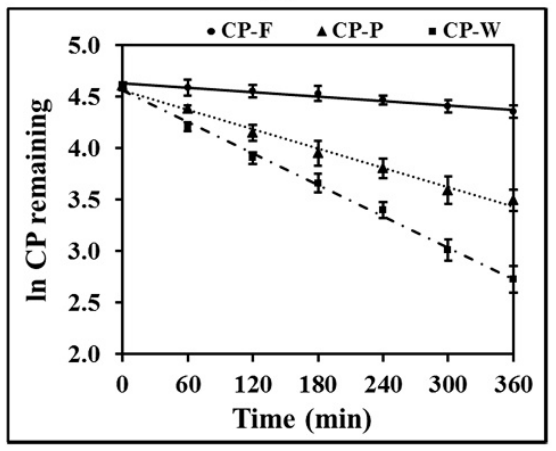

Figure 3. Degradation profiles of CP under UV light exposure, (a) zero order plots and (b) first order plots.

The degradation profiles of CP under UV light exposure are shown in Figure 2. Plotting the data according to the first order degradation, the linear relationship was obtained as shown in Figure 3b, with the $r^{2}$ close to 1, as shown in Table 3. From these results, the reaction rate constant of $\mathrm{CP}$ in $\mathrm{CP}-\mathrm{F}$ was shown to be significantly lower than that in CP-W and CP-P. The results demonstrate that nanofibrous film prevented the degradation of CP from UV light. It is also considered that the solid dosage form has UV protection properties significantly greater than the liquid, e.g., solution, dosage form.

Table 3. First order parameters of CP degradation under UV light exposure.

\begin{tabular}{ccc}
\hline \multirow{2}{*}{ Formulation } & \multicolumn{2}{c}{ Parameters } \\
\cline { 2 - 3 } & Rate Constant $\left(\times \mathbf{1 0}^{-\mathbf{4}} \mathbf{m i n}^{-\mathbf{1}}\right)$ & $\boldsymbol{r}^{\mathbf{2}}$ \\
\hline $\mathrm{CP}-\mathrm{F}$ & $6.88 \pm 0.48^{\mathrm{c}}$ & 0.96 \\
$\mathrm{CP}-\mathrm{P}$ & $30.36 \pm 3.40^{\mathrm{b}}$ & 0.99 \\
$\mathrm{CP}-\mathrm{W}$ & $50.93 \pm 2.95^{\mathrm{a}}$ & 0.99 \\
\hline
\end{tabular}

${ }^{*}$ Different letters are significantly different $(p<0.05)$.

\subsection{Long-Term Stability of CP-F}

According to World Health Organization [32], the recommendation of the testing condition for the long-term stability of products was $25 \pm 2{ }^{\circ} \mathrm{C} / 60 \pm 5 \% \mathrm{RH}$ or $30 \pm 2{ }^{\circ} \mathrm{C} /$ $75 \pm 5 \%$ RH for a minimum period of 12 or 6 months, respectively. In this present study, the long-term storage was conducted at an average temperature of $25 \pm 2{ }^{\circ} \mathrm{C}$ for a period 
of 12 months. To compare the effects of temperature and humidity, a high temperature of $45^{\circ} \mathrm{C}$ was used. A humidity of $75 \%$ was selected from climatic zones IV and compared with the low humidity of $30 \%$. Thus, the storage conditions of $25^{\circ} \mathrm{C} / 30 \% \mathrm{RH}, 25^{\circ} \mathrm{C} / 75 \% \mathrm{RH}$, and $45{ }^{\circ} \mathrm{C} / 30 \% \mathrm{RH}$ were used for a period of 12 months. The changes in physicochemical properties, i.e., color, morphology, internal structure, molecular interaction, mechanical properties, and mucoadhesive properties were investigated. The gradual changes in $\mathrm{CP}$ content in CP-F kept at the three conditions were also determined.

\subsection{Color Changes after Long-Term Storage}

The color parameters of $\mathrm{CP}-\mathrm{F}$ investigated by the colorimetric measurements are shown in Table 4. Initially, CP-F was white as a high value of $\mathrm{L}^{*}$ was obtained. For the degree of green-red, CP-F was achromatic as the $\mathrm{a}^{*}$ value was close to 0 , and for the degree of blue-yellow, CP-F was slightly blue as a negative $b^{*}$ value was presented. The differences between the $\mathrm{L}^{*}, \mathrm{a}^{*}$, and $\mathrm{b}^{*}$ values of $\mathrm{CP}-\mathrm{F}$ stored at $25^{\circ} \mathrm{C} / 30 \% \mathrm{RH}$ were not significant, indicating that the color of CP-F kept at $25^{\circ} \mathrm{C} / 30 \% \mathrm{RH}$ for 12 months was not changed. The $\mathrm{L}^{*}$ value of $\mathrm{CP}-\mathrm{F}$ stored at $45^{\circ} \mathrm{C} / 30 \% \mathrm{RH}$ was the lowest compared to other conditions, indicating a significant decrease in the lightness of the samples. CP-F kept at $25^{\circ} \mathrm{C} / 75 \% \mathrm{RH}$ and $45^{\circ} \mathrm{C} / 30 \% \mathrm{RH}$ showed a high negative $\mathrm{a}^{*}$ value and a high positive $\mathrm{b}^{*}$ value, indicating the green and yellow of this sample was changed. It has been reported that the nanofibrous films containing PVA can possibly change into yellow or brown after thermal decomposition [33]. Therefore, the color change of CP-F was probably due to the decomposition of PVA which was present in the films. Among various storage conditions, no significant differences in the $\Delta \mathrm{E}$ values were detected. As the $\Delta \mathrm{E}$ value was lower than 3 , the color change was difficult to distinguish by human eye perception [34].

Table 4. Color parameter of CP-F at initial measurement and after storage at various conditions for 12 months.

\begin{tabular}{ccccc}
\hline \multirow{2}{*}{ Conditions } & \multicolumn{4}{c}{ Color Parameter } \\
\cline { 2 - 5 } & $\mathbf{L}^{*}$ & $\mathbf{A}^{*}$ & $\mathbf{B}^{*}$ & $\Delta \mathbf{E}$ \\
\hline Initial & $55.15 \pm 0.93^{\mathrm{a}}$ & $-0.08 \pm 0.05^{\mathrm{a}}$ & $-2.17 \pm 0.06^{\mathrm{c}}$ & - \\
$25^{\circ} \mathrm{C} / 30 \% \mathrm{RH}$ & $55.69 \pm 0.87^{\mathrm{a}}$ & $-0.07 \pm 0.04^{\mathrm{a}}$ & $-2.01 \pm 0.08^{\mathrm{c}}$ & $1.03 \pm 1.00^{\mathrm{a}}$ \\
$25^{\circ} \mathrm{C} / 75 \% \mathrm{RH}$ & $55.92 \pm 0.26^{\mathrm{a}}$ & $-0.18 \pm 0.03^{\mathrm{b}}$ & $-1.18 \pm 0.03^{\mathrm{a}}$ & $1.56 \pm 0.68^{\mathrm{a}}$ \\
$45^{\circ} \mathrm{C} / 30 \% \mathrm{RH}$ & $52.61 \pm 0.39^{\mathrm{b}}$ & $-0.30 \pm 0.06^{\mathrm{c}}$ & $-1.66 \pm 0.10^{\mathrm{b}}$ & $2.21 \pm 0.64^{\mathrm{a}}$ \\
\hline${ }^{*}$ Different letters are significantly different $(p<0.05)$ for color parameter at the different conditions.
\end{tabular}

\subsection{Morphology Changes after Long-Term Storage}

The SEM images of surface morphology and the diameter of the nanofibers in the nanofibrous films before and after keeping at the test storage conditions are presented in Figure 4. Initially, CP-F exhibited a smooth fibrous structure with a diameter range in nanosize, without any undesirable parts. After storage at $25^{\circ} \mathrm{C} / 30 \% \mathrm{RH}$ for 12 months, $\mathrm{CP}-\mathrm{F}$ showed slight defects of a straight line. However, no significant difference in average diameter was observed. The average diameters of $237 \pm 57$ and $267 \pm 72 \mathrm{~nm}$ were found for $\mathrm{CP}-\mathrm{F}$ at initial measurement and after storage at $25^{\circ} \mathrm{C} / 30 \% \mathrm{RH}$ for 12 months, respectively. 
(a)

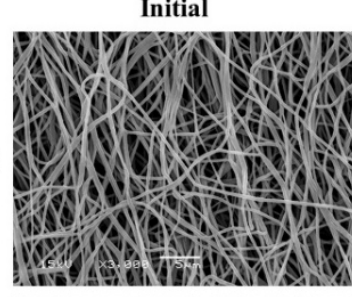

(b)

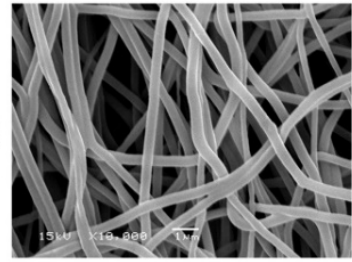

(c)

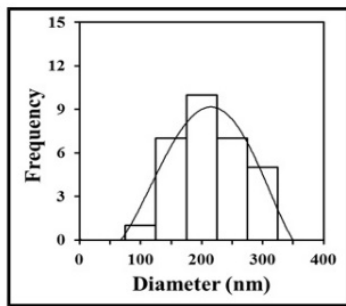

$25^{\circ} \mathrm{C} / 30 \% \mathrm{RH}$
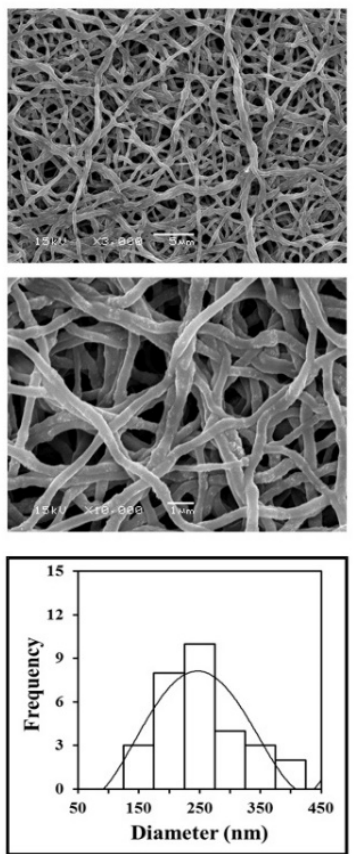

$25^{\circ} \mathrm{C} / 75 \% \mathrm{RH}$
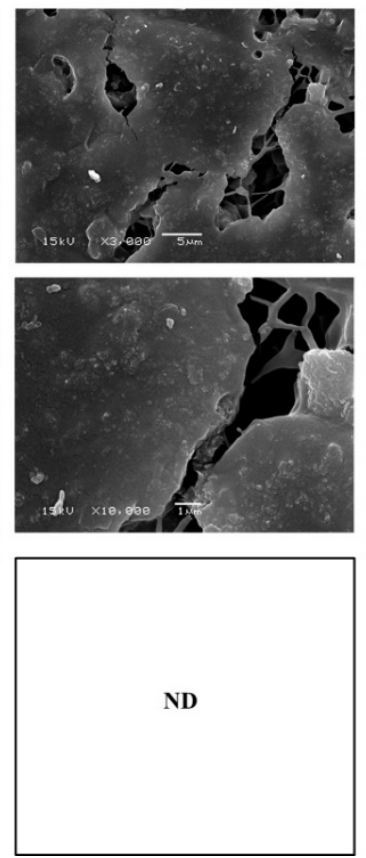

$45^{\circ} \mathrm{C} / 30 \%$ RH
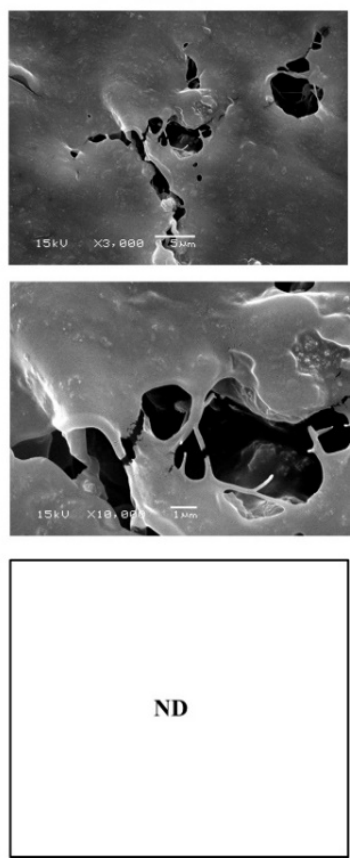

Figure 4. SEM images of CP-F at initial measurement and after storage at various conditions for 12 months, (a) at $3000 \times$ magnification, (b) at 10,000 $\times$ magnification, and (c) the average diameter (ND: not detectable).

After storage at $25{ }^{\circ} \mathrm{C} / 75 \% \mathrm{RH}$ for 12 months, $\mathrm{CP}-\mathrm{F}$ exhibited different morphology from the initial measurement, and the fibrous structure was changed. Nanofibers fused together and the structure of the fibers in nanosize was almost absent. The nanofibers could not keep the original structure. These phenomena also happened with $\mathrm{CP}-\mathrm{F}$ after storage at $45^{\circ} \mathrm{C} / 30 \% \mathrm{RH}$ for 12 months. This $\mathrm{CP}-\mathrm{F}$ showed the merging of the nanofibers. It was found that the remaining fibers showed discontinued and tear line structure. From these results, we considered that high temperature and high humidity are the important factors that affect the morphology of CP-F. It has been reported that high temperature can destroy the PVA-based nanofibrous film [35]. In the present study, the main composition of the nanofibers of CP-F was PVA and PVP and the results revealed that CP-F, after being subjected to high temperatures, became brittle, and the structure of the nanosized fibers was absent.

\subsection{Internal Structure Changes after Long-Term Storage}

The XRD patterns of intact $\mathrm{CP}$ and $\mathrm{CP}-\mathrm{F}$ before and after storage are displayed in Figure 5. Intact $\mathrm{CP}$ exhibited sharp identical peaks at $14^{\circ}, 23^{\circ}$, and $28^{\circ}$, indicating that the internal structure of $\mathrm{CP}$ was a crystalline form. The crystalline peaks of $\mathrm{CP}$ were absent in the XRD pattern of the freshly prepared CP-F. The disappearance of the $\mathrm{CP}$ crystalline peaks indicated that the drug was well incorporated in the nanofibrous film by electrospinning technique, and $\mathrm{CP}$ was converted from a crystalline state to an amorphous state. This halo pattern was also found in $\mathrm{CP}-\mathrm{F}$ after storage at $25^{\circ} \mathrm{C} / 30 \% \mathrm{RH}$ for 12 months, indicating that $\mathrm{CP}$ recrystallization did not occur during a long-term period of storage in this condition. 


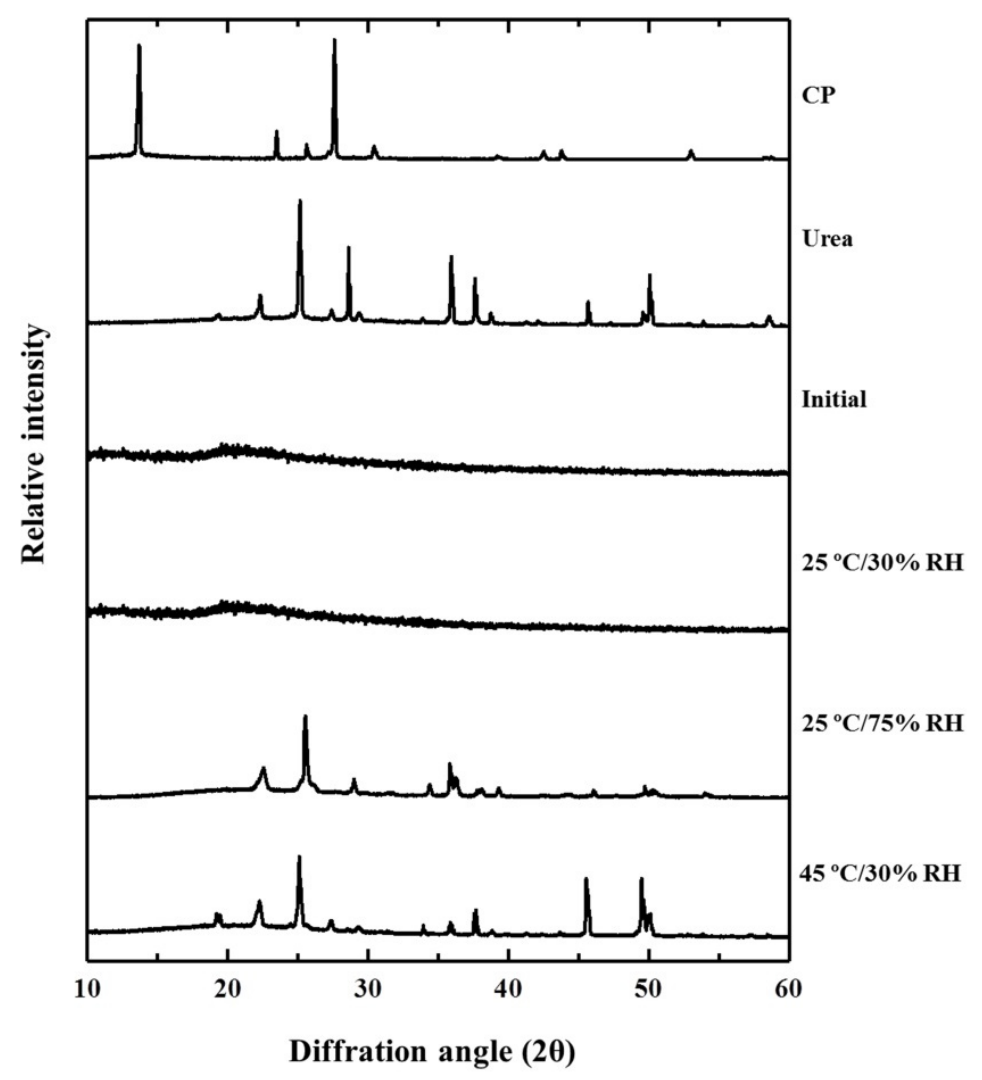

Figure 5. X-ray diffraction (XRD) patterns of CP-F after storage at various conditions for 12 months in comparison to the initial $\mathrm{CP}-\mathrm{F}, \mathrm{CP}$, and urea.

However, the XRD patterns of the stored CP-F under $25^{\circ} \mathrm{C} / 75 \% \mathrm{RH}$ and $45^{\circ} \mathrm{C} / 30 \%$ $\mathrm{RH}$ showed high identical crystalline peaks of $\mathrm{CP}$ at $22^{\circ}$ and $25^{\circ}$. Moreover, the XRD peaks at $46^{\circ}, 49^{\circ}$, and $50^{\circ}$ of $\mathrm{CP}-\mathrm{F}$ after storage at $45^{\circ} \mathrm{C} / 30 \% \mathrm{RH}$ were of higher intensity than that of $\mathrm{CP}$-F storage at $25^{\circ} \mathrm{C} / 75 \% \mathrm{RH}$. These peaks possibly related to urea as they resemble the peak patterns of urea powder. Generally, $\mathrm{CP}$ dissociated into hydrogen peroxide and urea [36]. The degradation products of hydrogen peroxide are oxygen and water [37] and these products may be lost during storage. Urea was the degradation product that remained in the formulation. The amorphous urea had partially recrystallized as the crystalline form under the storage conditions; hence some crystalline peaks of urea were visible. Recrystallization of drug and polymer during storage can occur [38]. Storage conditions such as temperature and humidity could trigger molecular mobility of the drug, which might accelerate the recrystallization of the amorphous drug $[39,40]$. Moreover, rearrangement of the amorphous state to the crystalline phase can be accompanied by the thermo-oxidation process in the solid state [41]. The results of the present study suggest that high temperature and high humidity accelerated the degradation of $\mathrm{CP}$, and increased drug recrystallization.

\subsection{Thermal Behavior Changes after Long-Term Storage}

The thermal behavior of CP-F before and after storage in the different conditions characterized by DSC are shown in Figure 6. It was found that the DSC thermogram of intact $\mathrm{CP}$ displayed a sharp endothermic peak at $92{ }^{\circ} \mathrm{C}$. Two broad endothermic curves of the blank nanofibrous film were observed at 68 and $213^{\circ} \mathrm{C}$. The DSC thermogram of CP-F showed two broad peaks similarly to the blank, however, the peaks were slightly shifted. The first endothermic broad peak of CP-F appeared at approximately $87^{\circ} \mathrm{C}$ and another broad peak appeared at about $194^{\circ} \mathrm{C}$. This might be due to an interaction between $\mathrm{CP}$ and the excipients in the nanofibrous film. In addition, the absence of the melting $\mathrm{CP}$ peak in 
the $\mathrm{CP}-\mathrm{F}$ thermogram suggested that $\mathrm{CP}$ was dispersed into the nanofibrous film as an amorphous form.

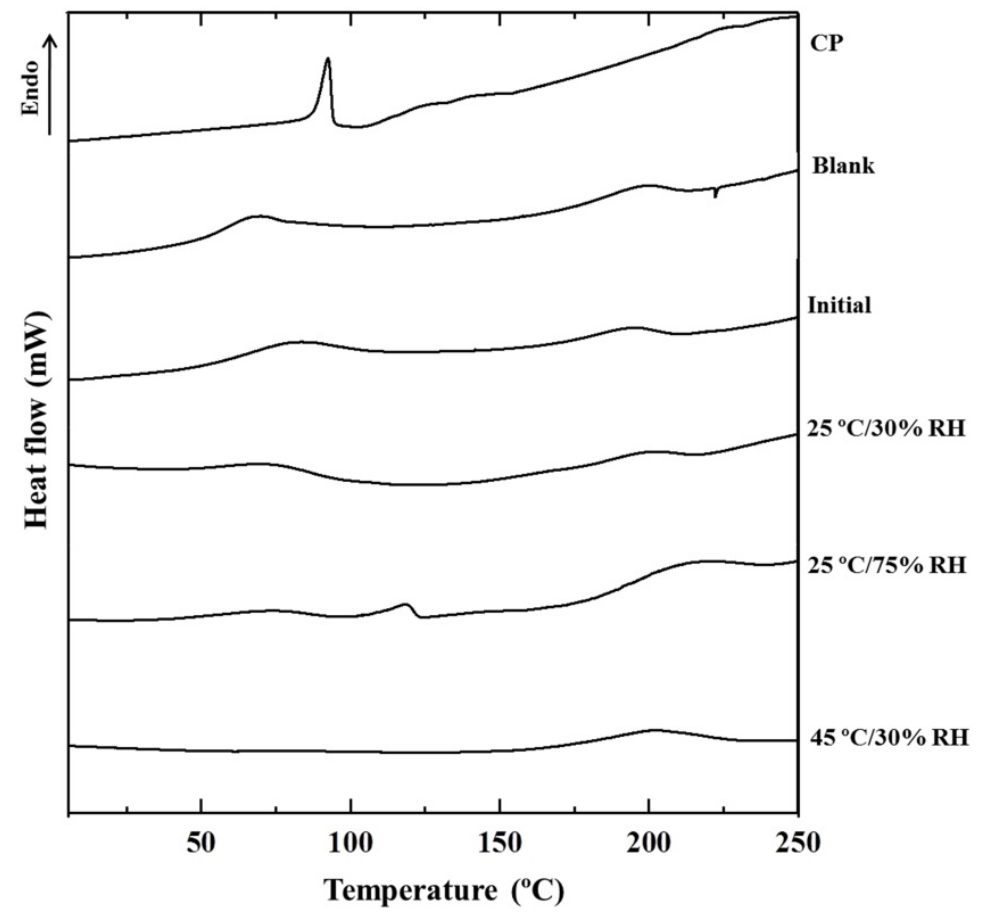

Figure 6. Differential scanning calorimetry (DSC) thermograms of CP-F after storage at various conditions for 12 months, in comparison to the initial CP-F, CP, and blank nanofibrous film (blank).

After long-term storage at $25{ }^{\circ} \mathrm{C} / 30 \% \mathrm{RH}$, the DSC thermogram of $\mathrm{CP}-\mathrm{F}$ looked similar to that of the initial state of $\mathrm{CP}-\mathrm{F}$, with no melting peaks representing the crystalline characteristics of $\mathrm{CP}$ or polymers observed. The results imply that the amorphous $\mathrm{CP}$ remained stable in the nanofibrous film. However, the endothermic peak at $118{ }^{\circ} \mathrm{C}$ was observed in the CP-F stored at $25{ }^{\circ} \mathrm{C} / 75 \% \mathrm{RH}$. It has been reported that the polymer type and storage condition have a strong impact on solid-state properties [42]. PVA and PVP are hydrophilic polymers and often hygroscopic in nature: these polymers can absorb a high amount of moisture from the environment [43-45]. Hence, it is feasible that PVA and PVP present in CP-F would absorb water from the high humidity of $75 \% \mathrm{RH}$. In the meantime, degradation of $\mathrm{CP}$ yields hydrogen peroxide and urea, which can further break down into water and ammonia [37]. Therefore, the endothermic peak of the CP-F thermogram that appeared at $118^{\circ} \mathrm{C}$ might represent the water dehydration peak of the film after sorption of the water from the degradation of $\mathrm{CP}$, and the high humidity of the storage container during storage time.

\subsection{Molecular Interaction Changes after Long-Term Storage}

The interaction at the molecular level between a drug and a polymer is essential to explain the stability in solid dosage forms [46]. FTIR is a useful technique for the determination of molecular interactions between drugs and polymers. Figure 7 shows the FTIR spectra of CP-F before and after storage in different conditions, obtained within the range of $4000 \mathrm{~cm}^{-1}$ to $600 \mathrm{~cm}^{-1}$. The FTIR spectrum of CP showed the band at $1670 \mathrm{~cm}^{-1}$ referred to $\mathrm{C}=\mathrm{O}$ stretching. The bands at 1627,3448 , and $3356 \mathrm{~cm}^{-1}$ were corresponded to the $\mathrm{N}-\mathrm{H}$ stretching of $\mathrm{CP}$. The FTIR spectrum of blank nanofibrous film represented absorption peaks at $3290 \mathrm{~cm}^{-1}$ that referred to the $\mathrm{O}-\mathrm{H}$ stretching vibration of the hydroxyl group of the base polymer. The peaks at 1444 and $2944 \mathrm{~cm}^{-1}$ referred to $-\mathrm{CH}_{2}$ bending and $\mathrm{C}-\mathrm{H}$ stretching of PVA, respectively $[47,48]$. The absorption peaks at $1696 \mathrm{~cm}^{-1}$ referred to $\mathrm{C}=\mathrm{O}$ from the amide group of PVP [49]. The peak around $1044 \mathrm{~cm}^{-1}$ was $\mathrm{Si}-\mathrm{O}$ 
stretching [50]. The FTIR spectral pattern of CP-F was similar to that of blank nanofibrous film. The absorption peaks at around 1446-1440 $\mathrm{cm}^{-1}$ referred to $\mathrm{CH}_{2}$ bending of PVA. The weak broad band of the hydroxyl group at the $3500-3200 \mathrm{~cm}^{-1}$ spectral region was assigned to the $\mathrm{O}-\mathrm{H}$ stretching vibration of the hydroxyl group of PVA. A low-frequency peak of the $\mathrm{C}=\mathrm{O}$ stretching vibrations spectrum of PVP from 1696 to $1650 \mathrm{~cm}^{-1}$ was observed and a strong absorption peak at $1092 \mathrm{~cm}^{-1}$ was presented.

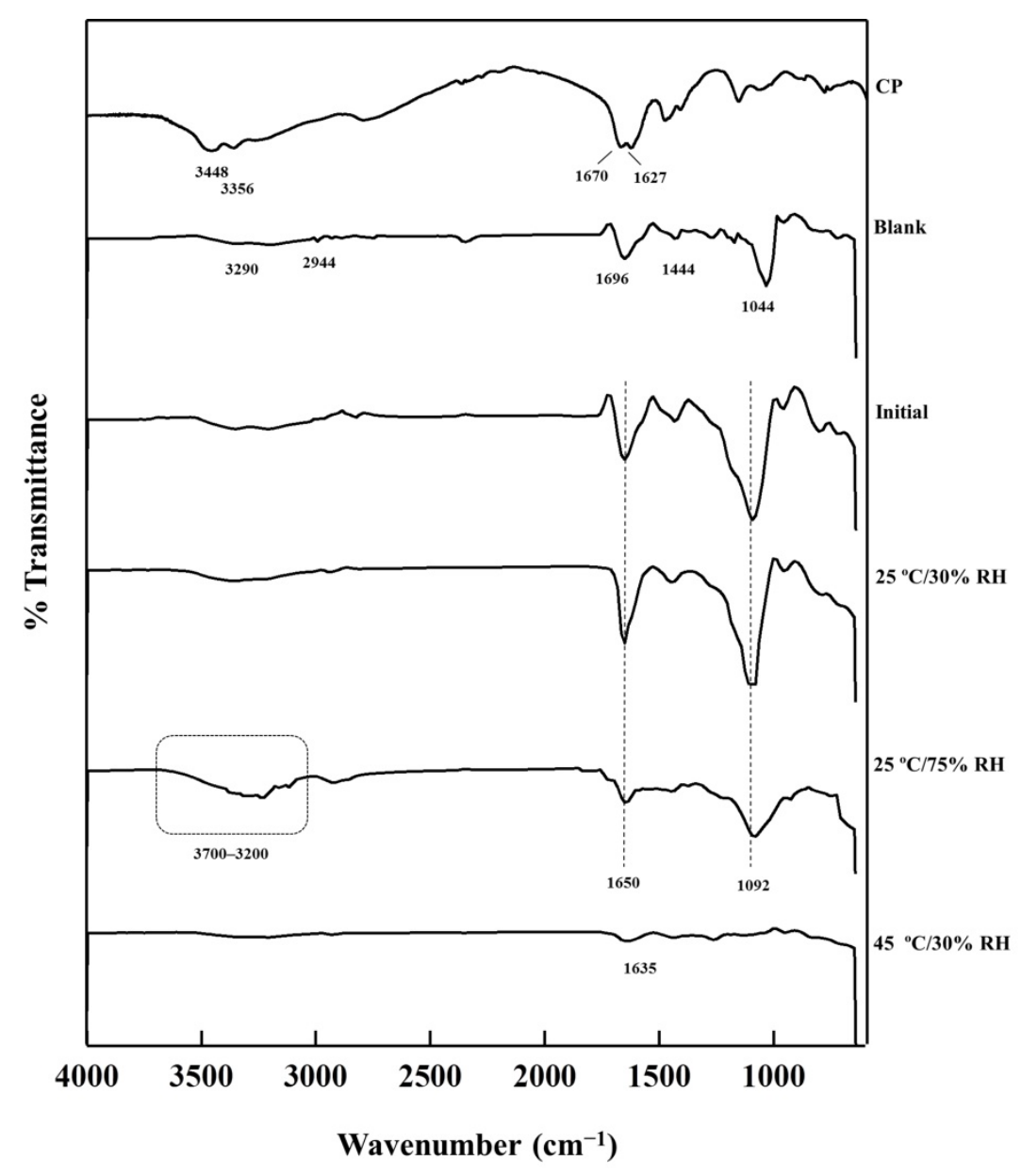

Figure 7. Fourier transform infrared spectroscopy (FTIR) spectrums of CP-F in the different storage conditions in comparison to the initial CP-F, CP, and blank nanofibrous film (blank).

It was noted that the low-frequency of the $\mathrm{C}=\mathrm{O}$ stretching vibration at $1696 \mathrm{~cm}^{-1}$ of PVP in the blank nanofibrous film was shifted to $1650 \mathrm{~cm}^{-1}$ after loading CP to the nanofibrous film. This might be due to the interaction of the peroxide and PVP [51]. In addition, the strong absorption peak at $1044 \mathrm{~cm}^{-1}$ was due to the siloxane bridge ( $\mathrm{Si}-\mathrm{O}-\mathrm{Si}$ ) of the formulations. However, after loading $\mathrm{CP}$ to the nanofibrous film, this peak was shifted to $1092 \mathrm{~cm}^{-1}$, indicating a molecular interaction with the siloxane bridge. It has been reported that hydrogen peroxide could form a strong hydrogen bond to the oxygen of the siloxane bridge [52]. The spectral shifted peak at $1092 \mathrm{~cm}^{-1}$ represented the interactions of hydrogen peroxide from the molecules of $\mathrm{CP}$, that adsorbed on the silica surface to the siloxane bridge of the silica gel.

The FTIR spectrum of CP-F after storage at $25{ }^{\circ} \mathrm{C} / 75 \%$ RH showed an increase in the intensity of the peak at $3700-3200 \mathrm{~cm}^{-1}$. As previously mentioned, the water content of CP-F could be increased due to the water sorption of CP-F during storage in high humidity, therefore the band in the region of $3700-3200 \mathrm{~cm}^{-1}$ was corresponded to the $-\mathrm{OH}$ stretching vibration of the hydrogen bonds of the water molecules [53]. However, the FTIR spectrum of CP-F after storage at $45{ }^{\circ} \mathrm{C} / 30 \%$ RH exhibited very low intensity at 
the region of $3700-3200 \mathrm{~cm}^{-1}$, and the peak at $1092 \mathrm{~cm}^{-1}$ was absent. Only the stretching vibration of $\mathrm{N}-\mathrm{H}$ at $1635 \mathrm{~cm}^{-1}$ was found. These results suggested that high temperature could lead to a decrease in the water content and hydroxyl groups [54]. Therefore, many peaks were missing due to damage from heat. Interestingly, the FTIR spectrum of CP-F after storage at $25{ }^{\circ} \mathrm{C} / 30 \% \mathrm{RH}$ for 12 months showed no change in the molecular interaction during the storage period. This result suggested the condition of $25^{\circ} \mathrm{C} / 30 \% \mathrm{RH}$ was suitable for keeping CP-F.

\subsection{Mechanical Properties Changes after Long-Term Storage}

The effect of storage conditions on the mechanical properties of CP-F is of interest. The results as shown in Table 5 indicate that there was no statistically significant difference in tensile strength, elongation at break, and Young's modulus values between initial measurements and after storage at $25{ }^{\circ} \mathrm{C} / 30 \% \mathrm{RH}$. However, changes in the mechanical properties were detected in CP-F stored at $25{ }^{\circ} \mathrm{C} / 75 \% \mathrm{RH}$ and at $45{ }^{\circ} \mathrm{C} / 30 \% \mathrm{RH}$. The higher-humidity storage led to a decrease in tensile strength and Young's modulus value of CP-F, while the percentage of elongation at break was increased compared to the initial value. This was likely related to the water molecules in CP-F, which decrease the original interactions in the polymer matrix of the nanofibrous film [55]. Water molecules can restructure the chain networks through inter- and intramolecular hydrogen bonds [56], resulting in an increase in elongation at break and a decrease in tensile strength and Young's modulus values. In the case of the high temperature of $45^{\circ} \mathrm{C} / 30 \% \mathrm{RH}$ storage, the decrease in tensile strength, elongation at break, and Young's modulus values were found. It could be noted that the higher temperature affected the strength and flexibility of the nanofibrous film, resulting in more brittle film. This result corresponds to the FTIR pattern showing the negative effect of the storage conditions on the molecular interaction of $\mathrm{CP}-\mathrm{F}$, thus, changes in mechanical properties also occurred.

Table 5. Mechanical properties of CP-F at initial measurement and after storage at various conditions for 12 months.

\begin{tabular}{cccc}
\hline Conditions & $\begin{array}{c}\text { Tensile Strength } \\
(\mathbf{M P a})^{*}\end{array}$ & Elongation (\%) & $\begin{array}{c}\text { Young's Modulus } \\
(\mathbf{M P a})\end{array}$ \\
\hline Initial & $2.46 \pm 0.21^{\mathrm{a}}$ & $40.43 \pm 3.56^{\mathrm{b}}$ & $6.08 \pm 0.51^{\mathrm{a}}$ \\
$25^{\circ} \mathrm{C} / 30 \% \mathrm{RH}$ & $2.17 \pm 0.18^{\mathrm{a}}$ & $35.96 \pm 5.37^{\mathrm{b}}$ & $6.03 \pm 0.51^{\mathrm{a}}$ \\
$25^{\circ} \mathrm{C} / 75 \% \mathrm{RH}$ & $1.09 \pm 0.17^{\mathrm{b}}$ & $52.97 \pm 3.11^{\mathrm{a}}$ & $2.05 \pm 0.33^{\mathrm{b}}$ \\
$45^{\circ} \mathrm{C} / 30 \% \mathrm{RH}$ & $0.28 \pm 0.02^{\mathrm{c}}$ & $13.01 \pm 1.99^{\mathrm{c}}$ & $2.15 \pm 0.23^{\mathrm{b}}$ \\
\hline${ }^{*}$ Different letters are significantly different $(p<0.05)$ for mechanical properties at the different conditions.
\end{tabular}

\subsection{Adhesive Property Changes after Long-Term Storage}

The adhesion of the nanofibrous film is important as it affects the intended function for tooth whitening. The freshly prepared CP-F could adhere to the surface of the mucosa and the measured adhesive force was found to be $0.79 \pm 0.07 \mathrm{~N}$. After storage at $25^{\circ} \mathrm{C} / 30 \%$ $\mathrm{RH}$ for 12 months, the formulation did not show a significant difference in the adhesive properties of the film from its initial value. The adhesive force of the stored film was $0.75 \pm$ $0.06 \mathrm{~N}$. The adhesive force of CP-F after storage at $25^{\circ} \mathrm{C} / 75 \% \mathrm{RH}$ and $45^{\circ} \mathrm{C} / 30 \% \mathrm{RH}$ for 12 months was decreased to $0.54 \pm 0.03 \mathrm{~N}$ and $0.31 \pm 0.05 \mathrm{~N}$, respectively. It was therefore suggested that the humidity and temperature influenced the adhesive properties of CP-F.

\subsection{CP Remaining after Long-Term Storage}

The stability of $\mathrm{CP}$ during long-term storage under different conditions is presented as degradation profiles, as shown in Figure 8. After storage for 12 months at $25^{\circ} \mathrm{C} / 75 \% \mathrm{RH}$ and $45{ }^{\circ} \mathrm{C} / 30 \% \mathrm{RH}, \mathrm{CP}$ content was significantly decreased from the initial value $(p<0.05)$. However, $\mathrm{CP}$ in CP-F kept at $25^{\circ} \mathrm{C} / 30 \% \mathrm{RH}$ showed significantly higher stability than that kept at the other storage conditions. A slight reduction in $\mathrm{CP}$ was observed, without a significant difference in CP content between time intervals. At the end of the test period 
of 12 months, the remaining CP content in this condition was found to be up to $96.23 \pm$ $3.05 \%$, followed by that kept at $25^{\circ} \mathrm{C} / 75 \% \mathrm{RH}(68.37 \pm 4.17 \%)$. Stored at $45^{\circ} \mathrm{C} / 30 \% \mathrm{RH}$, $\mathrm{CP}$ could not be found after 6 months had passed, suggesting that all CP might have been completely degraded. The results also indicate that temperature had a higher effect on $\mathrm{CP}$ degradation than humidity.

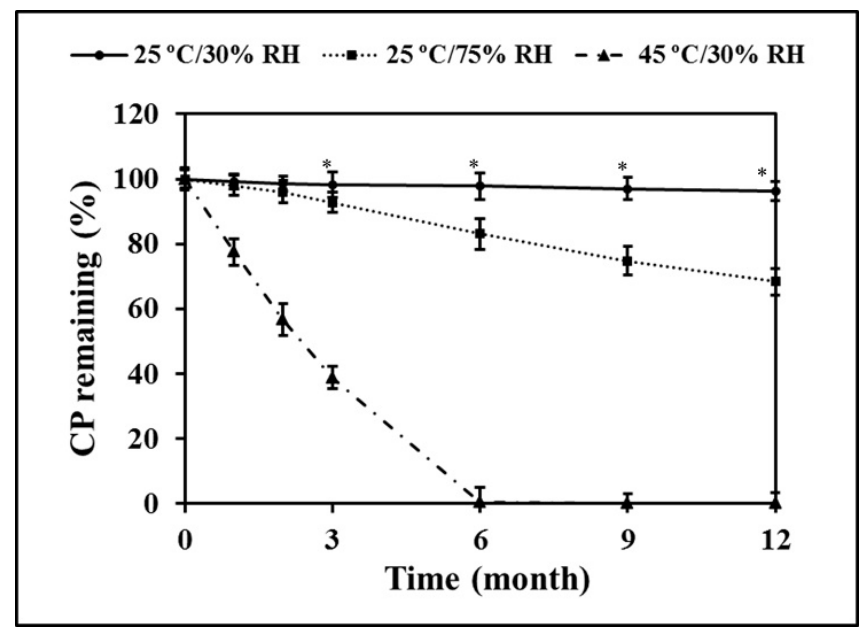

Figure 8. $\mathrm{CP}$ remaining in $\mathrm{CP}-\mathrm{F}$ during long-term storage in the various conditions. * Significant difference in the amount of $\mathrm{CP}$ in comparison to other storage conditions $(p<0.05)$.

According to the short-term stability under stress conditions of 60,70 , and $80{ }^{\circ} \mathrm{C}$ as mentioned above, the calculated shelf-life of $\mathrm{CP}$ in $\mathrm{CP}-\mathrm{F}$, obtained from the predicted degradation rate of Arrhenius plots at $25^{\circ} \mathrm{C}$, is approximately 1 year. This result is in agreement with the actual measured value of $\mathrm{CP}$ in $\mathrm{CP}-\mathrm{F}$ stored at $25^{\circ} \mathrm{C} / 30 \% \mathrm{RH}$. However, at $25{ }^{\circ} \mathrm{C} / 75 \% \mathrm{RH}$, the results show that $\mathrm{CP}$ degradation occurred after 3 months. This result indicates that the presence of humidity in the environment can increase the $\mathrm{CP}$ degradation rate.

From these results, it is suggested that the most suitable condition for keeping CP-F is that of low temperature and low humidity. In storage at high temperature, the loss of CP was increased. This can influence the efficacy of the product, leading to a lower clinical efficacy than expected. Moreover, the tooth whitening treatment would likely fail to achieve the desired outcome. The temperature and humidity, as described in the present study, played an important role in CP concentration, as well as in the performance of the nanofibrous film to deliver CP to the teeth. Therefore, the formulation should be stored in a proper condition to ensure a satisfactory clinical response. Furthermore, the formulation should be carefully packed in a humidity-impermeable container to provide a permanent barrier to protect the drug from degradation caused by humidity.

\section{Conclusions}

The degradation kinetics of $\mathrm{CP}$ in the prepared $\mathrm{CP}-\mathrm{F}, \mathrm{CP}-\mathrm{P}$, and $\mathrm{CP}-\mathrm{W}$ followed the first order reaction. $\mathrm{CP}$ in $\mathrm{CP}-\mathrm{F}$ possessed significantly higher stability than $\mathrm{CP}-\mathrm{P}$, and $\mathrm{CP}-\mathrm{W}$. The half-life of CP in CP-F was $6.5 \pm 0.2$ years, much higher than that of CP-P (13.8 \pm 0.8 days) and CP-W (1.3 \pm 0.2 days). Moreover, the nanofibrous film showed high efficiency to protect CP from light. Long-term storage of CP-F under high temperature and humidity can cause a color change, destroy the structure of nanofibers, and decrease the mechanical and adhesive properties of $\mathrm{CP}-\mathrm{F}$, as well as increase the chemical degradation of CP. High humidity enhances water absorption of CP-F leading to the degradation of $\mathrm{CP}$. Among the three storage test conditions, the storage condition of $25{ }^{\circ} \mathrm{C} / 30 \% \mathrm{RH}$ was the most suitable for stabilizing CP-F. In conclusion, the results of the present study suggest that loading CP in a nanofibrous film and storage in the suitable conditions of low temperature and low humidity can potentially enhance CP stability. 
Supplementary Materials: The followings are available online at https:/ / www.mdpi.com/article/ 10.3390/pharmaceutics13040449/s1, Figure S1: HPLC chromatogram of (a) triphenylphosphine oxide and residual of triphenylphosphine after oxidation by CP and (b) HPLC chromatogram of triphenylphosphine.

Author Contributions: Conceptualization, S.O., P.C., and A.K.; methodology, S.O., P.C., and A.K.; validation, S.O.; formal analysis, S.O. and A.K.; investigation, A.K.; writing-original draft preparation, A.K.; writing—review and editing, S.O. and A.K.; supervision, S.O.; project administration, S.O.; funding acquisition, S.O. All authors have read and agreed to the published version of the manuscript.

Funding: This research was funded by Thailand Research Fund through the Research and Researcher for Industry (Grant No. PHD58I0012), the Agricultural Research Development Agency, and the Higher Education Research Promotion and National Research University Project of Thailand, Office of the Higher Education Commission.

Institutional Review Board Statement: Not applicable.

Informed Consent Statement: Not applicable.

Data Availability Statement: Data are available upon request to the corresponding author.

Acknowledgments: The authors are grateful to the Research Center of Pharmaceutical Nanotechnology, Chiang Mai University, Thailand, for equipment and facility support.

Conflicts of Interest: The authors declare no conflict of interest.

\section{References}

1. Joiner, A.; Luo, W. Tooth colour and whiteness: A review. J. Dent. 2017, 67, S3-S10. [CrossRef]

2. Gold, S.I. Early origins of hydrogen peroxide use in oral hygiene: A historical note. J. Periodontol. 1983, 54, 247. [CrossRef]

3. Farrell, G.; McNichols, W. Efficacy of various medicaments in the treatment of Vincent's stomatitis. J. Am. Med. Assoc. 1937, 108, 630-633. [CrossRef]

4. Bonesi, C.D.M.; Ulian, L.S.; Balem, P.; Angeli, V.W. Carbamide peroxide gel stability under different temperature conditions: Is manipulated formulation an option? Braz. J. Pharm. Sci. 2011, 47, 719-724. [CrossRef]

5. Joiner, A. The bleaching of teeth: A review of the literature. J. Dent. 2006, 34, 412-419. [CrossRef]

6. Dahl, J.E.; Pallesen, U. Tooth bleaching-A critical review of the biological aspects. Crit. Rev. Oral Biol. Med. 2003, 14, 292-304. [CrossRef]

7. Kawamoto, K.; Tsujimoto, Y. Effects of the hydroxyl radical and hydrogen peroxide on tooth bleaching. J. Endod. 2004, 30, 45-50. [CrossRef] [PubMed]

8. Christensen, G.J. Are snow-white teeth really so desirable? J. Am. Dent. Assoc. 2005, 136, 933-935. [CrossRef]

9. Putt, M.S.; Proskin, H.M. Custom tray application of peroxide gel as an adjunct to scaling and root planing in the treatment of periodontitis: Results of a randomized controlled trial after six months. J. Clin. Dent. 2013, 24, 100-107.

10. Bentley, C.D.; Leonard, R.H.; Crawford, J.J. Effect of whitening agents containing carbamide peroxide on cariogenic bacteria. J. Esthet. Dent 2000, 12, 33-37. [CrossRef]

11. Yao, C.S.; Waterfield, J.D.; Shen, Y.; Haapasalo, M.; MacEntee, M.I. In vitro antibacterial effect of carbamide peroxide on oral biofilm. J. Oral Microbiol. 2013, 5, 1-6.

12. Polydorou, O.; Hellwig, E.; Auschill, T.M. The effect of different bleaching agents on the surface texture of restorative materials. Oper. Dent. 2006, 31, 473-480. [CrossRef]

13. Buchalla, W.; Attin, T. External bleaching therapy with activation by heat, light or laser-A systematic review. Dent. Mater. 2007, 23, 586-596. [CrossRef] [PubMed]

14. Matis, B.A.; Matis, J.I.; Wang, Y.; Monteiro, S.; Al-Qunaian, T.A.; Millard, R. Labeled vs. actual concentration of bleaching agents. Oper. Dent. 2013, 38, 334-343. [CrossRef]

15. Blanco, M.; Coello, J.; Sánchez, M.J. Experimental design for optimization of peroxide formulation stability and cost. J. Surfactants Deterg. 2006, 9, 341-347. [CrossRef]

16. Francine, K.V.M.; Celso Afonso, K.J.; Eduardo, G.R.; Rubem Beraldo, D.S.; Fernando Freitas, P.; Keiichi, H. Storage temperature influences the carbamide peroxide concentration of at home bleaching agents. Biomed. J. Sci. Tech. Res. 2018, 9, 6898-6902.

17. Kurthy, R. The science of whitening gel refrigeration. A KöR Whitening Sci. Pap. 2016, 10, 9-15.

18. Shetab Boushehri, M.A.; Dietrich, D.; Lamprecht, A. Nanotechnology as a platform for the development of injectable parenteral formulations: A comprehensive review of the know-hows and state of the art. Pharmaceutics 2020, 12, 510. [CrossRef]

19. Kriegel, C.; Arrechi, A.; Kit, K.; McClements, D.J.; Weiss, J. Fabrication, functionalization, and application of electrospun biopolymer nanofibers. Crit. Rev. Food Sci. Nutr. 2008, 48, 775-797. [CrossRef]

20. Persano, L.; Camposeo, A.; Tekmen, C.; Pisignano, D. Industrial upscaling of electrospinning and applications of polymer nanofibers: A review. Macromol. Mater. Eng. 2013, 298, 504-520. [CrossRef] 
21. Tian, Y.; Orlu, M.; Woerdenbag, H.J.; Scarpa, M.; Kiefer, O.; Kottke, D.; Sjöholm, E.; Öblom, H.; Sandler, N.; Hinrichs, W.L.J.; et al. Oromucosal films: From patient centricity to production by printing techniques. Expert Opin. Drug Deliv. 2019, 16, 981-993. [CrossRef]

22. Okonogi, S.; Kaewpinta, A.; Rades, T.; Müllertz, A.; Yang, M.; Khongkhunthian, S.; Chaijareenont, P. Enhancing stability and tooth bleaching activity of carbamide peroxide by electrospun nanofibrous film. Pharmaceuticals 2020, 13, 381. [CrossRef] [PubMed]

23. World Health Organization. Guidelines for stability testing of pharmaceutical products containing well established drug substances in conventional dosage forms (Annex 5). In WHO Technical Report Series; World Health Organization: Geneva, Switzerland, 1996; pp. 65-80.

24. Kaewpinta, A.; Khongkhunthian, S.; Chaijareenont, P.; Okonogi, S. Preparation and characterization of rice gels containing tooth bleaching agent. Drug Discov. Ther. 2018, 12, 275-282. [CrossRef]

25. Stark, G.; Fawcett, J.P.; Tucker, I.G.; Weatherall, I.L. Instrumental evaluation of color of solid dosage forms during stability testing. Int. J. Pharm. 1996, 143, 93-100. [CrossRef]

26. Jantrawut, P.; Boonsermsukcharoen, K.; Thipnan, K.; Chaiwarit, T.; Hwang, K.M.; Park, E.S. Enhancement of antibacterial activity of orange oil in pectin thin film by microemulsion. Nanomaterials 2018, 8, 545. [CrossRef]

27. Kaewpinta, A.; Khongkhunthian, S.; Chaijareenont, P.; Okonogi, S. Tooth whitening efficacy of pigmented rice gels containing carbamide peroxide. Drug Discov. Ther. 2018, 12, 126-132. [CrossRef]

28. Gimeno, P.; Bousquet, C.; Lassu, N.; Maggio, A.F.; Civade, C.; Brenier, C.; Lempereur, L. High-performance liquid chromatography method for the determination of hydrogen peroxide present or released in teeth bleaching kits and hair cosmetic products. J. Pharm. Biomed. Anal. 2015, 107, 386-393. [CrossRef]

29. Yoshioka, S.; Stella, V.J. Stability of Drug and Dosage Forms; Springer: Boston, MA, USA, 2002; pp. 1-270.

30. Hunt, J.P.; Taube, H. The photochemical decomposition of hydrogen peroxide. J. Phys. Chem. 1952, 74, 5999-6002.

31. Lima, D.A.N.L.; Aguiar, F.H.B.; Liporoni, P.C.S.; Munin, E.; Ambrosano, G.M.B.; Lovadino, J.R. In vitro evaluation of the effectiveness of bleaching agents activated by different light sources. J. Prosthodont. 2009, 18, 249-254. [CrossRef]

32. World Health Organization. Stability testing of active pharmaceutical ingredients and finished pharmaceutical products (Annex 10). In WHO Technical Report Series, No. 1010; World Health Organization: Geneva, Switzerland, 2018; pp. 310-351.

33. Huang, L.; Wang, S. Effects of heat treatment on tensile properties of high-strength poly(vinyl alcohol) fibers. J. Appl. Polym. Sci. 2000, 78, 237-242. [CrossRef]

34. Johnston, W.M.; Kao, E.C. Assessment of appearance match by visual observation and clinical colorimetry. J. Dent. Res. 1989, 68, 819-822. [CrossRef]

35. Wijanarko, T.A.W.; Kusumaatmaja, A.; Chotimah, R.; Triyana, K. Effect of heat treatment on morphology and crystallinity of electrospun poly(vinyl alcohol) nanofibers. Am. Inst. Phys. Conf. Proc. 2016, 1755, 1-4.

36. Moraes, R.R.; Marimon, J.L.M.; Schneider, L.F.J.; Correr Sobrinho, L.; Camacho, G.B.; Bueno, M. Carbamide peroxide bleaching agents: Effects on surface roughness of enamel, composite and porcelain. Clin. Oral Investig. 2006, 10, 23-28. [CrossRef]

37. Ranganathan, S.; Sieber, V. Recent advances in the direct synthesis of hydrogen peroxide using chemical catalysis-A review. Catalysts 2018, 8, 379. [CrossRef]

38. Seif, S.; Franzen, L.; Windbergs, M. Overcoming drug crystallization in electrospun fibers—Elucidating key parameters and developing strategies for drug delivery. Int. J. Pharm. 2015, 478, 390-397. [CrossRef] [PubMed]

39. Feng, X.; Ye, X.; Park, J.B.; Lu, W.; Morott, J.; Beissner, B.; Lian, Z.J.; Pinto, E.; Bi, V.; Porter, S.; et al. Evaluation of the recrystallization kinetics of hot-melt extruded polymeric solid dispersions using an improved Avrami equation. Drug Dev. Ind. Pharm. 2015, 41, 1479-1487. [CrossRef] [PubMed]

40. Ueda, H.; Kadota, K.; Imono, M.; Ito, T.; Kunita, A.; Tozuka, Y. Co-amorphous Formation Induced by Combination of Tranilast and Diphenhydramine Hydrochloride. J. Pharm. Sci. 2017, 106, 123-128. [CrossRef] [PubMed]

41. Polaskova, M.; Peer, P.; Cermak, R.; Ponizil, P. Effect of thermal treatment on crystallinity of poly(ethylene oxide) electrospun fibers. Polymers 2019, 11, 1384. [CrossRef]

42. Rumondor, A.C.F.; Stanford, L.A.; Taylor, L.S. Effects of polymer type and storage relative humidity on the kinetics of felodipine crystallization from amorphous solid dispersions. Pharm. Res. 2009, 26, 2599-2606. [CrossRef]

43. Peresin, M.S.; Habibi, Y.; Vesterinen, A.H.; Rojas, O.J.; Pawlak, J.J.; Seppälä, J.V. Effect of moisture on electrospun nanofiber composites of poly(vinyl alcohol) and cellulose nanocrystals. Biomacromolecules 2010, 11, 2471-2477. [CrossRef]

44. Ueda, H.; Aikawa, S.; Kashima, Y.; Kikuchi, J.; Ida, Y.; Tanino, T.; Kadota, K.; Tozuka, Y. Anti-plasticizing effect of amorphous indomethacin induced by specific intermolecular interactions with PVA copolymer. J. Pharm. Sci. 2014, 103, 2829-2838. [CrossRef]

45. Prudic, A.; Ji, Y.; Luebbert, C.; Sadowski, G. Influence of humidity on the phase behavior of API/polymer formulations. Eur. J. Pharm. Biopharm. 2015, 94, 352-362. [CrossRef]

46. Tran, T.T.D.; Tran, P.H.L. Molecular interactions in solid dispersions of poorly water-soluble drugs. Pharmaceutics 2020, $12,745$. [CrossRef]

47. Alwan, T.J.; Toma, Z.A.; Kudhier, M.A.; Ziadan, K.M. Preparation and characterization of the PVA nanofibers produced by electrospinning. Madr. J. Nanotechnol. Nanosci. 2016, 1, 1-3. [CrossRef]

48. Subramanian, U.M.; Kumar, S.V.; Nagiah, N.; Sivagnanam, U.T. Fabrication of polyvinyl alcohol-polyvinylpyrrolidone blend scaffolds via electrospinning for tissue engineering applications. Int. J. Polym. Mater. Polym. Biomater. 2014, 63, 462-470. [CrossRef] 
49. Huang, S.; Zhou, L.; Li, M.C.; Wu, Q.; Kojima, Y.; Zhou, D. Preparation and properties of electrospun poly (vinyl pyrrolidone)/cellulose nanocrystal/silver nanoparticle composite fibers. Materials 2016, 9, 523. [CrossRef]

50. Wei, Y.; Zhang, W.; Li, S.; Patel, A.C.; Wang, C. Electrospinning of porous silica nanofibers containing silver nanoparticles for catalytic applications. Chem. Mater. 2007, 19, 1231-1238.

51. Panarin, E.F.; Kalninsh, K.K.; Pestov, D.V. Complexation of hydrogen peroxide with polyvinylpyrrolidone: Ab initio calculations Eur. Polym. J. 2001, 37, 375-379. [CrossRef]

52. Zegliński, J.; Piotrowski, G.P.; Piekoś, R. A study of interaction between hydrogen peroxide and silica gel by FTIR spectroscopy and quantum chemistry. J. Mol. Struct. 2006, 794, 83-91. [CrossRef]

53. Ping, Z.H.; Nguyen, Q.T.; Chen, S.M.; Zhou, J.Q.; Ding, Y.D. States of water in different hydrophilic polymers—DSC and FTIR studies. Polymer 2001, 42, 8461-8467. [CrossRef]

54. Vasudevan, P.; Thomas, S.; Biju, P.R.; Sudarsanakumar, C.; Unnikrishnan, N.V. Synthesis and structural characterization of sol-gel derived titania/poly (vinyl pyrrolidone) nanocomposites. J. Sol Gel Sci. Technol. 2012, 62, 41-46. [CrossRef]

55. Tian, H.; Yan, J.; Rajulu, A.V.; Xiang, A.; Luo, X. Fabrication and properties of polyvinyl alcohol/starch blend films: Effect of composition and humidity. Int. J. Biol. Macromol. 2017, 96, 518-523. [CrossRef] [PubMed]

56. Abral, H.; Chairani, M.K.; Rizki, M.D.; Mahardika, M.; Handayani, D.; Sugiarti, E.; Muslimin, A.N.; Sapuan, S.M.; Ilyas, R.A. Characterization of compressed bacterial cellulose nanopaper film after exposure to dry and humid conditions. J. Mater. Res. Technol. 2021, 11, 896-904. [CrossRef] 